\title{
Preweaning Calf Survival of a Nellore Beef Cattle Population
}

\author{
Jairo Azevedo Junior ${ }^{1}$, Juliana Petrini ${ }^{2}$, Gerson Barreto Mourão ${ }^{2} \&$ José Bento Sterman Ferraz $^{1}$ \\ ${ }^{1}$ Department of Veterinary Medicine, College of Animal Science and Food Engineering, University of São Paulo, \\ Pirassununga, SP, Brazil \\ ${ }^{2}$ Department of Animal Science, College of Agronomy "Luiz de Queiroz", University of São Paulo, Piracicaba, \\ SP, Brazil \\ Correspondence: Jairo Azevedo Junior, Avenida Pará, 955, Postal Code 77403-010, Gurupi, TO, Brazil. Tel: \\ 55-63-999-336-010. E-mail: jairo@zootecnista.com.br
}

Received: May 3, 2017

Accepted: June 14, $2017 \quad$ Online Published: July 15, 2017

doi:10.5539/jas.v9n8p51

URL: https://doi.org/10.5539/jas.v9n8p51

\begin{abstract}
The preweaning calf survival (SW) is one of the main economic bottlenecks of beef cattle rearing systems, however there is still few quantitative studies approaching this issue. Being a binary trait, genetic parameters for SW can be estimated considering continuous or categorical data under frequentist and Bayesian methods providing support for the selection and mating of animals in breeding programs. Therefore, the objectives in this study were to obtain and compare the variance component estimates for preweaning calf survival of calves in single-trait analyses and their correlations with a continuous trait in two-trait analyses. An amount of 25218 data of the categorical trait of calf survival until weaning (SW) and the continuous trait of weaning weight (WW) were collected between the years of 2000 and 2012 in six herds of Nellore cattle. Methods III of Henderson, Maximum Restricted Likelihood (REML), Bayesian Inference and Generalized Linear Mixed Model (GLMM) were tested. Variance components obtained in one-trait analyses were similar to those obtained in two-trait analyses. Estimates of heritability $\left(\mathrm{h}^{2}\right)$ obtained with different models for SW ranged from 0.0206 to 0.2644 . The comparison between different estimation methods in single or two-trait analysis models allows the conclusion that the most appropriate method for SW analysis was the Bayesian estimation under an animal model and assuming linear distribution for phenotypes of SW trait.
\end{abstract}

Keywords: categorical traits, continuous traits, estimation method, rearing system, Zebu catlle

\section{Introduction}

Preweaning calf mortality is one of the main economic bottlenecks of beef cattle rearing systems (Bourdon \& Golden, 2000). Mortality rate of calves can be influenced by calf sex (Corrêa et al., 2000); climate and management conditions; vigor and birth weight of calves; temperament, conformation of the breast unit and milk yield of the cows as well as by genetic aspects of the cow and the calf (Ray et al., 1989; Riley et al., 2001a, 2004). In Brazil, mortality rate averages of 8 and $4 \%$ were already reported for preweaning and post-weaning periods respectively (Euclides Filho, 2000). Specifically for Nellore cattle, the most important and populous zebu cattle in Brazil, losses of $6 \%$ (Corrêa et al., 2000) and 7.99\% (Schmidek et al., 2013) until weaning were reported for calves in extensive breeding. Nevertheless, few quantitative studies considering preweaning mortality rate have been conducted in such breed populations.

The trait called preweaning calf survival represents the mortality of calves at this stage of life (until to the weaning). It has a binomial distribution, assuming the phenotypes 0 or 1 for calves that died before weaning, and 1 or 2 for calves that were alive at weaning. Therefore, this trait has a threshold distribution of phenotypes that are grouped in few phenotypic classes.

Variance components and genetic parameters for categorical traits can be estimated in a one-trait or two-trait analyse under the assumption of linear (Forutan, Mahyari, \& Sargolzaei, 2015) or threshold distribution of phenotypes (Faria et al., 2010; Forutan, Mahyari, \& Sargolzaei, 2015), by using sire or animal models (Forutan, Mahyari, \& Sargolzaei, 2015); and by adopting restricted maximum likelihood (REML, Queiroz et al., 2011), Bayesian (Santana Jr. et al., 2013) or generalized linear mixed model approaches (GLMM, Forutan, Mahyari, \& Sargolzaei, 2015) as estimation methods. 
Besides being little studied in zebu breeds, such as the Nellore cattle, there is no definite consensus regarding the best methodology or combinations of methodologies to be adopted in the genetic analysis of preweaning calf survival. Therefore, the aim in this study was to estimate variance components for categorical survival until weaning trait of Nellore calves by using alternative models in single-trait analyses and their correlations with a continuous trait in two-trait analyses.

\section{Method}

The approval of the Ethics Committee on Animal Use was not necessary in this study because the data were obtained from an existing database.

\subsection{Animals and Data File}

The Nellore cattle data were provided by the Genetic Improvement Program of CFM Ltda and collected in six herds. The animals were kept in high quality pastures (40\% Brachiaria, Panicum maximum 50\%, and 10\% other forage) and received salt and mineral supplement until 18 months old. The breeding season, with duration of 90 days for heifers and 60 days for cows, was concentrate from October to January, depending on the beginning of the rainy season. Calves remained with their dams in high quality pastures until about 7 months old, when they were weaned.

Two traits were analyzed in this study: preweaning calf survival (SW) and weaning weight (WW, kg). Values of 1 were assigned for animals that survived until weaning, and 2 for otherwise. Only data from animals with known parents, with known age of the dam at birth, and animals born between the years 2000 and 2012 were considered. Animals conceived by embryo transfer were excluded. Outliers for age at first calving, WW and YW were detected $(\mu<3 \sigma$ or $\mu>3 \sigma)$ and eliminated. After discarding records with incomplete and inconsistent data, a description of the traits evaluated in this study is shown in Table 1. Observations recorded between 140 and 270 days of the calf's age were considered as weaning records.

Table 1. Description of data for preweaning calf survival (SW) and weaning weight (WW, $\mathrm{kg}$ ) traits evaluated in Nellore cattle and for contemporary group at birth (CG_B)

\begin{tabular}{llll}
\hline & SW & WW & CG_B \\
\hline $\mathrm{N}$ & 25,218 & 25,218 & 457 \\
Mean & 1.05 & 176.15 & 55 \\
Standard deviation & 0.21 & 59.19 & - \\
Minimum & 1.00 & 0.00 & 6 \\
Maximum & 2.00 & 272.00 & 1249 \\
\hline
\end{tabular}

The contemporary groups at birth (CG_B) was formed by animals born in the same herd, year and season, reared at the same management group at birth and of the same sex. Contemporary groups with progenies of only two bulls and with less than five animals were discarded. It was also discarded CG_B with only one phenotypic class. A description of the CG after its consolidation is listed in Table 1.

\subsection{Genetic Analyses}

Estimates of variance components were obtained from different mixed models regarding their genetic structure, estimation method and the assumed distribution of the data (Table 2). 
Table 2. Definition of the different models used for genetic analyses of preweaning survival (SW) and weaning weight (WW) in Nellore cattle

\begin{tabular}{lllll}
\hline Model & Genetic Struture & Estimation Method & Data Distribution & Software \\
\hline One-trait analysis & & & & \\
SHL & Sire Model (S) & IIIH (H) & Linear (L) & SAS \\
SRL & Sire Model (S) & REML (R) & Linear (L) & ASREML \\
ARL & Animal Model (A) & REML (R) & Linear (L) & ASREML \\
ABL & Animal Model (A) & GIBBS (B) & Linear (L) & GIBBS3F90 \\
ABT & Animal Model (A) & GIBBS (B) & Threshold (T) & THRGIBBS3F90 \\
AGTLo & Animal Model (A) & GLMM (G) & Threshold-Logit (TLo) & ASREML \\
AGTPr & Animal Model (A) & GLMM (G) & Threshold -Probit (TPr) & ASREML \\
Two-trait analysis & & & & \\
ARLL & Animal Model (A) & REML (R) & Linear-Linear (LL) & ASREML \\
ABLL & Animal Model (A) & GIBBS (B) & Linear-Linear (LL) & GIBBS3F90 \\
ABLT & Animal Model (A) & GIBBS (B) & Linear- Threshold (LC) & THRGIBBS3F90 \\
\hline
\end{tabular}

Note. IIIH: Method III of Henderson; REML: Restricted Estimated Maximum Likelihood; GLMM: Generalized Linear Mixed Models; GIBBS: Gibbs sampling (Bayesian Inference).

\subsubsection{Genetic Structure: Sire Model vs. Animal Model}

The animal model considered for the categorical and continuous traits in the genetic analyses under the classic linear model methodology followed the generic mathematical model:

$$
\mathrm{y}=\mathrm{X} \beta+\mathrm{Z}_{1} \mathrm{a}+\mathrm{Z}_{2} \mathrm{~m}+\mathrm{Z}_{3} \mathrm{c}+\mathrm{Z}_{4} \mathrm{~d}+\mathrm{e}
$$

Where, $y$ is the vector of response variables; $\beta$ is the vector of fixed effects, including covariates; a is the vector of the random genetic additive direct effects; $m$ is the vector of random genetic additive maternal effects; $c$ is the vector of random effects of maternal permanent environment; $d$ is the vector of random effects of contemporary group at birth; and $\mathrm{e}$ is the vector of random residual effects inherent to each observation; $\mathrm{X}, \mathrm{Z}_{1}, \mathrm{Z}_{2}, \mathrm{Z}_{3}$ and $\mathrm{Z}_{4}$ represent the incidence matrices for fixed and random effects, associating respectively the elements of $\beta, \mathrm{a}, \mathrm{m}, \mathrm{c}$ and $\mathrm{d}$ to the response variable.

The assumptions for the model were: $\mathrm{E}[\mathrm{y}]=\mathrm{X} \beta ; \mathrm{E}[\mathrm{a}]=0 ; \mathrm{E}[\mathrm{m}]=0 ; \mathrm{E}[\mathrm{c}]=0 ; \mathrm{E}[\mathrm{d}]=0 ; \mathrm{E}[\mathrm{e}]=0$; and

$$
\mathrm{V}\left[\begin{array}{c}
\mathrm{a} \\
\mathrm{m} \\
\mathrm{c} \\
\mathrm{d} \\
\mathrm{e}
\end{array}\right]=\left[\begin{array}{ccccc}
\mathrm{A} \sigma_{\mathrm{a}}^{2} & \mathrm{~A} \sigma_{\mathrm{am}} & 0 & 0 & 0 \\
\mathrm{~A} \sigma_{\mathrm{am}} & \mathrm{A} \sigma_{\mathrm{m}}^{2} & 0 & 0 & 0 \\
0 & 0 & \mathrm{I} \sigma_{\mathrm{c}}^{2} & 0 & 0 \\
0 & 0 & 0 & \mathrm{I} \sigma_{\mathrm{d}}^{2} & 0 \\
0 & 0 & 0 & 0 & \mathrm{I} \sigma_{\mathrm{e}}^{2}
\end{array}\right]
$$

Where, $\mathrm{A}$ is the matrix of genetic covariances among animals; I is the identity matrix; $\sigma_{\mathrm{a}}^{2}$ is the genetic additive direct variance; $\sigma_{\mathrm{m}}^{2}$ is the genetic additive maternal variance; $\sigma_{\mathrm{c}}^{2}$ is the variance due to maternal permanent environmental effect; $\sigma_{\mathrm{d}}^{2}$ is the variance due to the management group effect at birth (CG_B); and $\sigma_{\mathrm{e}}^{2}$ is the residual variance. The covariances among all the effects were assumed to be zero, except the covariance between direct and maternal genetic effects.

In the sire model used to analyze SW and WW traits, the animal direct effect was replaced by the direct effect of the sire; and the maternal genetic effects, maternal permanent environment as well as the covariance between the direct and maternal genetic effects were disregarded.

The 39884 animals in relationship matrix structure are 25218 progenies of 2071 sires and 12595 dams. It were verified parity orders from one up to seven for dams.

\subsection{Estimation Methods}

\subsubsection{Method III of Henderson (Henderson, 1953)}

The solution of equations for sire and animal models can be a difficult task and some simple methods can be adopted, as the method proposed by Henderson in 1953. Classically, this method was widely used until the 80's and does not use the relationship matrix to solve the mixed effects. Henderson's Method III, also called method of 
fitting constants, uses the reductions in the sums of squares of the complete model and of the submodels to estimate the variance components. Thus, the Henderson's Method III consists in finding the estimators for the variance components, setting up a system of equations from the differences between the reductions in the full model and sub-models, equating them to their respective expectation. Method III can be used for any mixed model and produces unbiased estimates of the variance components.

\subsubsection{Method of Restricted Estimated Maximum Likelihood (REML)}

In REML (Patterson \& Thompson, 1971), each observation is divided in two independent parts, the fixed and random effects, and the probability density function of the observations is given by the sum of the probability density functions of each part. The maximization of the portion from the probability density function associated to random effects in relation to the variance components eliminates the bias resulting of the loss of degrees of freedom in the estimation of fixed effects. The REML equations with balanced data are identical to ANOVA estimators that are non-biased and with minimum variance. The REML estimator considers the degrees of freedom involved in the estimation of fixed effects, and when REML is applied to unbalanced data, REML estimators can be biased (Searle, 1987). The REML estimators for each variance component are a function of estimates of the other components, and can only be found by iterative numerical methods. In this study, variance components obtained by REML methodology were obtained from analyses based on sire model and animal model by using AIREMLF90 (Misztal et al., 2015) and ASREML v4.1 (Gilmour et al., 2015) software.

\subsubsection{Method of Generalized Linear Mixed Models (GLMM, Nelder \& Wedderburn, 1972)}

Generalized Linear Models are an extension of linear models and constitute a number of techniques commonly studied separately. These models involve a variable response, explanatory variables and a random sample of $n$ observations. Systematic effects (fixed and random effects) are linearized by a function of the expected values (for example, Log, Probit and Logit functions), allowing to the fitted values to vary in the response amplitude. Variance components estimated by GLMM were obtained assuming a threshold distribution for the data and using ASREML program (Gilmour et al., 2015) with the link functions Probit and Logit. The residual variance for the Logit function was set at 3.289; and the residual variance in the Probit function was set at 1 .

\subsubsection{Gibbs Sampling (Gianola \& Foulley, 1983)}

Bayesian inference with Gibbs sampling approach has been used to estimate genetic parameters for categorical data on sire and maternal grandfather-sire models. Some difficulties can be verified in obtaining Gibbs chain convergence in animal models because the algorithm used is characterized as an iterative process (Faria et al., 2008). Nevertheless, Bayesian inference is recommended to obtain genetic correlations between categorical (survival and visual scores) and continuous traits (weights) through multi-trait analysis (Everling et al., 2014). In this study, the Bayesian approach was performed using the GIBBS3F90 program (Misztal et al., 2015) (assuming linear distribution of data) and THRIGIBBS3F90 program (Misztal et al., 2015) program (assuming threshold distribution of data). A total of 1000000 iterations were performed, with sampling interval every 10 interactions and burn in of 10000 iterations. Analyses of subsequent estimates were performed using the POSTGIBBS3F90 program (Misztal et al., 2015).

The analyses models and their effects (fixed and random) proposed for each trait are described in Table 3.

Table 3. Description of the analytical models used for genetic analyses of preweaning survival (SW) and weaning weight (WW) in Nellore cattle

\begin{tabular}{llllll}
\hline Trait & ANI & MAT & MPE & CG_B & MAP \\
\hline SW & R & R & R & F & F \\
WW & R & R & R & F & F \\
\hline
\end{tabular}

Note. $\overline{\mathrm{ANI}}=$ genetic additive direct effect; $\mathrm{MAT}=$ genetic additive maternal effect; $\mathrm{MPE}=$ maternal permanent environment; $C G \_B=$ contemporary group at birth; $\mathrm{MAP}=$ mother's age at calving (linear and quadratic effects covariates). $\mathrm{R}=$ random effect; $\mathrm{F}=$ fixed effect.

\subsection{Heritability Coefficient Estimates}

Two estimates of heritability were calculated for SW and WW traits in animal model analyses by using Equations (3) and (4): 


$$
\begin{gathered}
\mathrm{h}_{\mathrm{a}}^{2}=\left(\sigma_{\mathrm{a}}^{2}\right) /\left(\sigma_{\mathrm{a}}^{2}+\sigma_{\mathrm{m}}^{2}+\sigma_{\mathrm{a}, \mathrm{m}}+\sigma_{\mathrm{mpe}}^{2}+\sigma_{\mathrm{e}}^{2}\right) \\
\mathrm{h}_{\mathrm{t}}^{2}=\left(\sigma_{\mathrm{a}}^{2}+0.5 \sigma_{\mathrm{m}}^{2}+1.5 \sigma_{\mathrm{a}, \mathrm{m}}\right) /\left(\sigma_{\mathrm{a}}^{2}+\sigma_{\mathrm{m}}^{2}+\sigma_{\mathrm{a}, \mathrm{m}}+\sigma_{\mathrm{mpe}}^{2}+\sigma_{\mathrm{e}}^{2}\right)
\end{gathered}
$$

Where, $h_{a}{ }^{2}$ is the narrow sense heritability and $h_{t}{ }^{2}$ is the total heritability in the narrow sense, adjusted for maternal genetic effect $\left(\sigma_{\mathrm{m}}^{2}\right)$ and the existing covariance between direct and maternal genetic effects $\left(\sigma_{\mathrm{a}, \mathrm{m}}\right)$ verified for the trait. In addition, $\sigma_{\mathrm{a}}^{2}$ is the additive variance, $\sigma_{\mathrm{mpe}}^{2}$ is the variance of the maternal permanent effects, and $\sigma_{\mathrm{e}}^{2}$ is the residual variance.

In sire model analyses, the heritabilities for SW and WW traits were obtained from the Equation (5):

$$
\mathrm{h}_{\mathrm{a}}^{2}=\left(4 \sigma_{\mathrm{s}}^{2}\right) /\left(\sigma_{\mathrm{s}}^{2}+\sigma_{\mathrm{e}}^{2}\right)
$$

Where, $\mathrm{h}_{\mathrm{a}}{ }^{2}$ is the narrow sense heritability, $\sigma_{\mathrm{s}}^{2}$ is the sire variance and $\sigma_{\mathrm{e}}^{2}$ is the residual variance.

\subsection{Genetic Correlation Estimates}

Genetic correlations between SW and WW traits estimated in animal model and two-trait analyses were performed for ARL, ABL and ABT models to compare the Bayesian inference and REML estimation methods and the linear and threshold data distribution. Estimates of additive genetic correlations $\left(\mathrm{r}_{\mathrm{a}}\right)$ were obtained from the Equation (6):

$$
r_{a}=\sigma_{\mathrm{a}_{(\mathrm{SW}, \mathrm{WW})}} /\left(\sqrt{\sigma_{\mathrm{a}_{(\mathrm{SW})}^{2}}^{2}} \times \sqrt{\sigma_{\mathrm{a}_{(\mathrm{WW})}}^{2}}\right)
$$

Where, $\sigma_{\mathrm{a}(\mathrm{sw}, \mathrm{ww})}$ is the covariance between additive direct effects of SW and WW, $\sigma_{\mathrm{a}(\mathrm{sw})}^{2}$ is the SW additive variance and $\sigma_{\mathrm{a}(\mathrm{ww})}^{2}$ is the WW additive variance.

\section{Results and Discussion}

A death rate of $4.6 \%$ was determined for the preweaning period. The frequency of mortality was $1.65 \%, 0.92 \%$, $0.78 \%, 0.55 \%$ and $0.28 \%$ from the first to the fifth month, respectively. Approximately $36 \%$ of the 1161 deaths occurred until the first month, $56 \%$ until the second month, and $73 \%, 85 \%$ and $91 \%$ until the third, fourth and fifth month, respectively. This rate of survival from birth to weaning was lower than those observed for the progenies $(n=1142)$ of Nellore $\times$ Hereford $(98.9 \%)$, Gir $\times$ Hereford and Angus $\times$ Hereford $(96.8 \%)$ cows in the study of Riley et al. (2001a), but higher than the rates obtained for calves of crossbred Gray Brahman (92.3\%), Indu-Brazil (87.1\%) and Red Brahman (93.0\%) cows in the same study. Lower calving survival rates were also found by Guerra, Franke, and Blouin (2006), with values between 88 and 93\% obtained from calves ( $\mathrm{n}=5015)$ of a crossbreeding study involving Angus, Brahman, Charolais, Hereford, Gelbvieh and Simmental breeds. More recently, Casas, Thallman, and Cundiff (2011) reported a calving survival rate equal to $95.8 \%$ for progenies ( $\mathrm{n}=$ 2 395) of crosses among Hereford, Angus and MARC III dams and Hereford, Brahman, Boran, Tuli and Belgian Blue sires. Recently, a death rate of $3 \%$ was verified for Nellore calves in similar conditions of management and breeding in Brazil (Silva et al., 2016).

The generally lower calf mortality in Nellore and crossbred Nellore populations, especially in comparison to other Bos indicus breeds (such as Indu-Brazil; Riley et al., 2001a), can be due to the udder characteristics of Nellore cows (Riley et al., 2001b). According to Riley et al. (2001b), the smaller teats size and stronger udder attachment of Nellore crossbred than Indu-Brazil and Red Brahman crossbreds cows make the nursery easier. Also, inadequate vigor at birth (and consequent calf mortality) was observed in calves of cows with large udders and distended teats, although no cause-effect relationship between those was establish (Riley et al., 2004).

In addition, Nellore populations have low incidence of dystocia, which is the main cause of neonatal mortality (Azzam et al., 1993). Herein, only $4 \%$ of the deaths occurred in the first day of life, with a perinatal survival of $99.8 \%$. The highest incidence of calf mortality was verified at the third week of life $(n=100$ deaths, Figure 1). Silva et al. (2016) agree that most deaths occurre in the first 30 days of life and that calf weak-ness was the most frequent cause of death, followed by diarrhea and navel inflammation. 


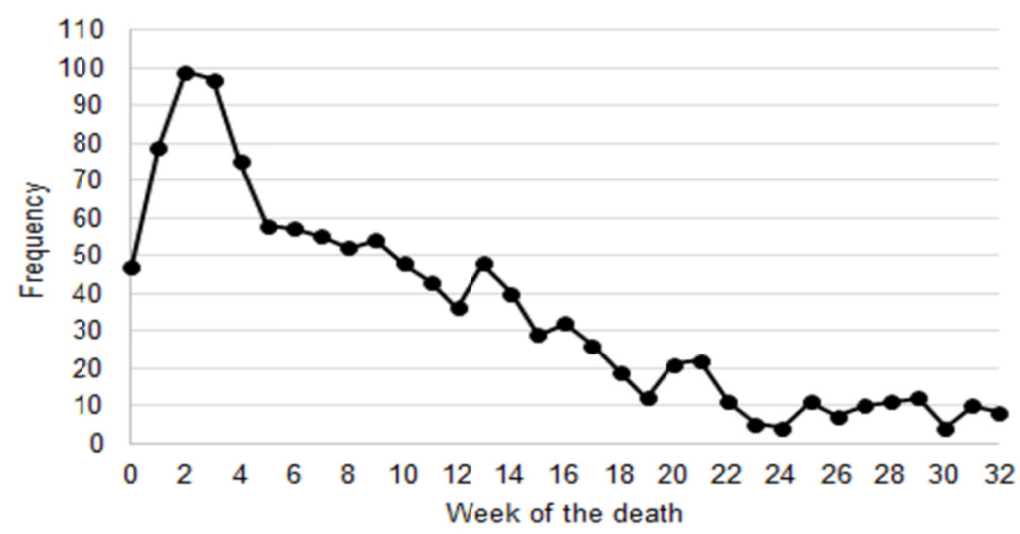

Figure 1. Number of calf deaths per week from birth to weaning in a Nellore cattle population

The incidence of death was higher for male calves than for female calves $(\mathrm{P}<0.0305$, Figure 2). This is consistent with the studies of Nix et al. (1998) and Guerra, Franke, and Blouin (2006). This behavior is often associated to a confound effect between calf sex and birth weight, and the association of the latter with dystocia (Nix et al., 1998). On the other hand, according to Riley et al. (2004), calf sex is more related to vigor at birth than preweaning mortality. In this study with 3631 Brahman calves, no effect of calf sex on preweaning mortality and no interaction between calf sex and dystocia were found. However, specifically in Nellore populations, the difference between male and female calves for preweaning mortality can be due to the occurrence of diarrhea and umbilicals myiasis in male calves extensively raised (Côrrea et al., 2000).

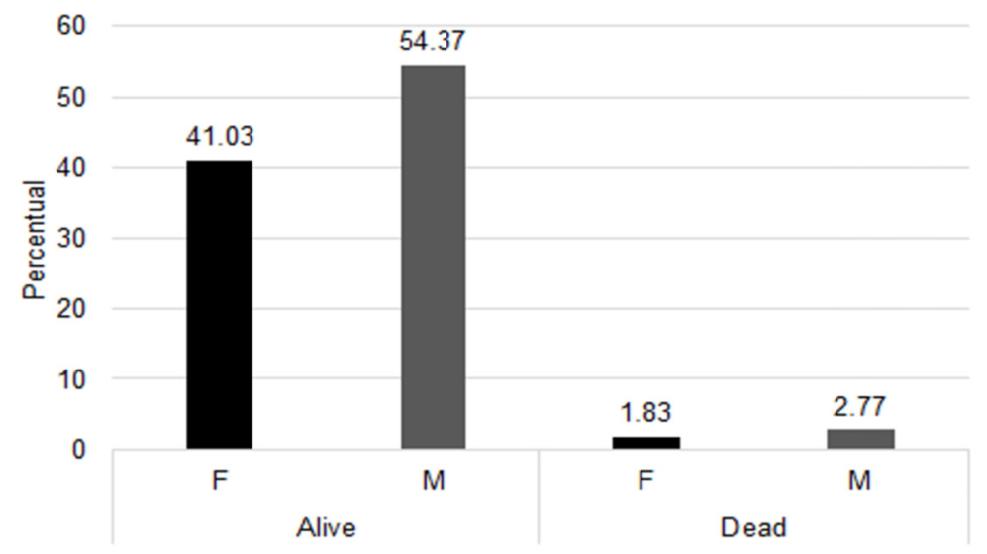

Figure 2. Preweaning survival rate of Nellore calves in each sex $(\mathrm{F}=$ females and $\mathrm{M}=$ males $)$

\subsection{Genetic Parameters for Preweaning Calf Survival}

Estimates of variance components and heritability for SW are presented in Table 4. There was a wide variation in estimates of the same variance component and heritability among the different methods. Higher estimates of direct heritability $\left(\mathrm{h}_{\mathrm{a}}{ }^{2}\right)$ were observed for ABT and SRL models whereas the lowest estimate of $\mathrm{h}_{\mathrm{a}}{ }^{2}$ was obtained with the AGTLo model. 
Table 4. Variance components and heritability for preweaning calf survival trait (SW) in a Nellore cattle population, estimated through different methodologies in one-trait analysis

\begin{tabular}{lllllllll}
\hline Model $^{1}$ & \multicolumn{1}{c}{$\sigma_{\mathrm{s}}^{2}$} & $\sigma_{\mathrm{a}}^{2}$ & \multicolumn{1}{c}{$\sigma_{\mathrm{m}}^{2}$} & \multicolumn{1}{c}{$\sigma_{\mathrm{a}, \mathrm{m}}$} & \multicolumn{1}{c}{$\sigma_{\mathrm{mpe}}^{2}$} & \multicolumn{1}{c}{$\sigma_{\mathrm{e}}^{2}$} & $\mathrm{~h}_{\mathrm{a}}^{2}$ & $\mathrm{~h}_{\mathrm{t}}^{2}$ \\
\hline SHL & 0.0016 & - & - & - & - & 0.0421 & 0.1550 & - \\
SRL & 0.0005 & - & - & - & - & 0.0432 & $0.0487(0.0119)$ & - \\
ARL & - & 0.0022 & 0.0005 & -0.0010 & $0.12 \mathrm{E}-7$ & 0.0421 & $0.0517(0.0124)$ & $0.0218(0.0075)$ \\
ABL & - & 0.0024 & 0.0007 & -0.0012 & 0.0003 & 0.0417 & $0.0536(0.0122)$ & $0.0206(0.0069)$ \\
ABT & - & 0.2861 & 0.0822 & -0.1509 & 0.0589 & 1.0047 & $0.1976(0.0201)$ & $0.0781(0.0379)$ \\
AGTLo & - & 0.0742 & 0.0358 & -0.0026 & 0.1386 & 3.289 & $0.0206(0.0232)$ & $0.0246(0.0291)$ \\
AGTPr & - & 0.0651 & 0.0023 & -0.0003 & 0.0021 & 1.00 & $0.0609(0.0226)$ & $0.0615(0.0291)$ \\
\hline
\end{tabular}

Note. $\sigma_{\mathrm{a}}^{2}$ : animal variance; $\sigma_{\mathrm{m}}^{2}$ : maternal genetic effect; $\sigma_{\mathrm{a}, \mathrm{m}}$ : covariance between direct and maternal genetic effects; $\sigma_{\mathrm{mpe}}^{2}$ : variance of the maternal permanent effects; $\sigma_{\mathrm{e}}^{2}$ is the residual variance; $\mathrm{h}_{\mathrm{a}}{ }^{2}$ : narrow sense heritability; $\mathrm{h}_{\mathrm{t}}{ }^{2}$ : total heritability. ${ }^{1}$ Models composition: (S) sire model, (A) animal model, (H) Method III of Henderson, (R) Restricted Estimated Maximum Likelihood, (B) Gibbs sampling (Bayesian Inference), (G) Generalized Linear Mixed Models, (L) Linear data distribution, (T) Threshold data distribution, (TLo) Threshold-Logit data distribution, (TPr) Threshold-Probit data distribution.

The inclusion of the additive relationship matrix among animals in the SRL model probably contributed to the lower sire variance, and consequently with the lower heritability for SW, in comparison to the estimates obtained with SHL model, also based on a sire model. The heritability obtained through SRL model was similar to the estimates obtained in the other models, indicating that the inclusion of the additive relationship matrix can improve the isolation of the genetic effects associated with the SW trait with a consequent increase in the reliability of their estimates. Smith et al. (1991), comparing methods of estimation of variance components for embryonic death, found that the likelihood procedures (including REML) have greater efficiency than Method III of Henderson for the estimation of variance components and genetic parameters from unbalanced data. The REML under an animal model is especially recommended for the estimation of variance components for low heritability traits, as is the case of SW trait (Carneiro Jr. et al., 2004).

The SRL and ARL models, which adopted REML method for the estimation of variance components (Table 4), provided similar estimates of heritability, indicating that the genetic gain obtained with the selection of sires or of the calf itself would be also similar.

A higher difference in heritability estimates were found between ABL and ABT models. Both are based on Bayesian methodology for estimation of variance components, but assumed different data distribution (linear or categorical). According to Van Tassel et al. (1998), Bayesian posterior distributions that are symmetric and similar to a normal distribution, as observed in Figure 3, indicate Gibbs chain convergence and appropriate estimation of variance components for the evaluated traits (in this case, SW). The analysis of SW considering a threshold distribution of phenotypes in a Bayesian approach (ABT model, Table 4) resulted in higher estimates of variance components and, consequently, in a higher heritability of SW, indicating that such a strategy, in comparison to the other methods, could result in a better identification and selection of genetically superior animals due to the higher heritability verified. This result agreed with the results obtained by Van Tassel et al. (1998). However, the heritability obtained in ABT model (Table 4) can be considered overstated and incorrect when compared to the values estimated through the other analytical models. In the studies of Van Tassel et al. (1998), Cole et al. (2007), and Forutan, Mahyari, and Sargolzaei (2015) which also involved threshold models, the frequency of each categorical class was higher than in the present study ( $4.6 \%$ of mortality versus $95.4 \%$ of survival). Thus, the overestimation of the variance components by using the ABT model can be due to the low frequency of some SW phenotypes. 
(a)

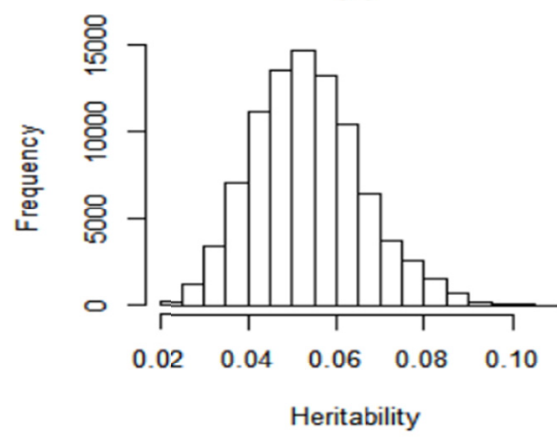

(c)

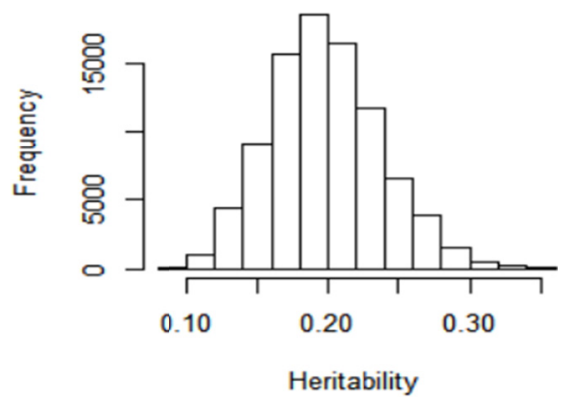

(b)

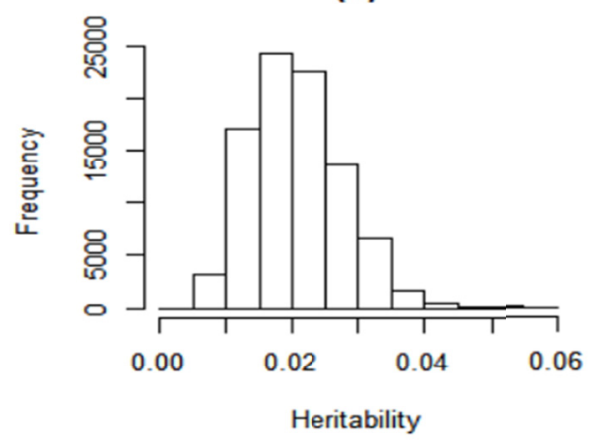

(d)

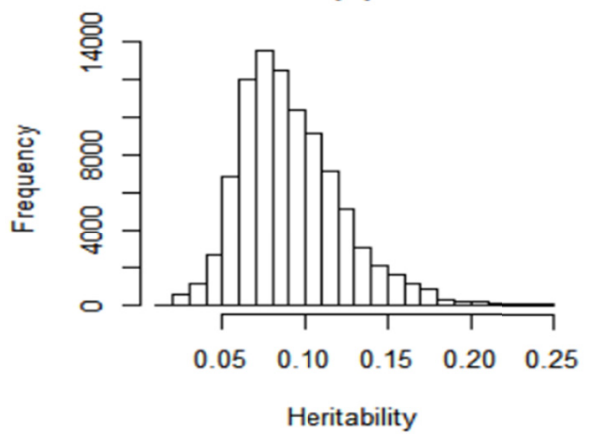

Figure 3. Distribution of posteriori estimates for direct heritability (a) and total heritability (b) for SW trait evaluated under the ABL model, and posteriori estimates for direct heritability (c) and total heritability (d) of SW trait evaluated under the ABT model in a Nellore cattle population

According to Forutan, Mahyari, and Sargolzaei (2015), the main reason for using linear model instead of threshold model is that the linear model is computationally less demanding beside the fact both models yield similar results in most cases.

The maternal variance and the variance due to the maternal permanent environment effects were much lower than the additive variance (Table 4). The estimates of covariance between direct genetic and maternal effects were also low, indicating that the contribution of calf's dam to the calf's ability to survive to the preweaning stage is very small in this population. Moreover, it was verified that the management of the calves has a positive impact on calf survival, especially during the first weeks of life when the incidence of calf deaths is higher (Figure 2). Hansen et al. (2003) reported that the maternal genetic variation for postnatal mortality is very small and difficult to be detected, even at young ages. Also, Goyache et al. (2003) did not found maternal influence on preweaning calf survival Asturiana de los Valles breed. However, the maternal effects on SW trait cannot be ignored. It was verified that the weighting of maternal effects and covariance between direct and maternal effects in the calculus of total heritability $\left(\mathrm{h}_{\mathrm{t}}{ }^{2}\right)$ resulted in estimates up to $42 \%$ lower to those obtained for direct heritability $\left(\mathrm{h}_{\mathrm{a}}{ }^{2}\right)$, with the exception of the models based GLMM method (AGTLo and AGTPr models).

The models based on the GLMM method, adjusted by using the Logit (AGTLo) and Probit (AGTPr) functions, provided different estimates of variance components between them and, consequently, different heritabilities for the SW trait (Table 4). The model fitted with the Logit link function resulted in a lower heritability estimate than that obtained through the model adjusted with the Probit function, probably due the error variance of Logit link function fixed in 3.289 .

The variance components and heritability for preweaning survival (SW) and weaning weight (WW), estimated through different methodologies in two-trait analyses, are presented in Table 5.

Direct $\left(\mathrm{h}_{\mathrm{a}}{ }^{2}\right)$ and total heritability $\left(\mathrm{h}_{\mathrm{t}}{ }^{2}\right)$ estimates for SW were similar to those obtained in single-trait analyses under ARL and ABL models (Table 4). As observed in single-trait analyses, ABT model in two-trait analysis (Table 5) overestimated the SW heritability, confirming that this method may not be suitable for the genetic evaluation of this trait. 
Table 5. Variance components and heritability for preweaning survival (SW) and weaning weight (WW) of Nellore cattle, estimated by different methodologies in two-trait analyses

\begin{tabular}{|c|c|c|c|c|c|c|c|c|c|}
\hline Model $^{1}$ & Trait & $\sigma_{\mathrm{a}}^{2}$ & $\sigma_{\mathrm{m}}^{2}$ & $\sigma_{\mathrm{a}, \mathrm{m}}$ & $\sigma_{\text {mpe }}^{2}$ & $\sigma_{\mathrm{e}}^{2}$ & $\mathrm{~h}_{\mathrm{a}}{ }^{2}$ & $\mathrm{~h}_{\mathrm{t}}^{2}$ & $\mathrm{r}_{\mathrm{a}}$ \\
\hline \multicolumn{10}{|l|}{$A R L$} \\
\hline & SW & 0.0015 & $0.1 \mathrm{E}-9$ & -0.0003 & 0.0009 & 0.0419 & 0.0339 & 0.0239 & -0.8873 \\
\hline & WW & 276.42 & 92.704 & -103.00 & 86.794 & 185.59 & 0.4309 & 0.3125 & \\
\hline \multicolumn{10}{|l|}{$A B L$} \\
\hline & SW & 0.0021 & 0.0004 & -0.0008 & 0.0001 & 0.0420 & $0.0466(0.0095)$ & $0.0249(0.0055)$ & $-0.6808(0.1105)$ \\
\hline & WW & 276.7 & 105.46 & -113.33 & 85.13 & 214.7 & $0.4071(0.0487)$ & $0.2822(0.0480)$ & \\
\hline \multicolumn{10}{|l|}{$A B T$} \\
\hline & SW & 1.8362 & 0.8504 & -1.2431 & 0.0156 & 0.9853 & $0.2644(0.1872)$ & $0.0830(0.0747)$ & $-0.3265(0.2486)$ \\
\hline & WW & 246.3 & 90.42 & -86.40 & 85.34 & 226.33 & $0.3760(0.0680)$ & $0.2869(0.0613)$ & \\
\hline
\end{tabular}

Note. $\sigma_{\mathrm{a}}^{2}$ : animal variance; $\sigma_{\mathrm{m}}^{2}$ : maternal genetic effect; $\sigma_{\mathrm{a}, \mathrm{m}}$ : covariance between direct and maternal genetic effects; $\sigma_{\text {mpe }}^{2}$ : variance of the maternal permanent effects; $\sigma_{\mathrm{e}}^{2}$ is the residual variance; $h_{\mathrm{a}}{ }^{2}$ : narrow sense heritability; $\mathrm{h}_{\mathrm{t}}{ }^{2}$ : total heritability; $\mathrm{r}_{\mathrm{a}}$ : genetic correlation. ${ }^{1}$ Models composition: (A) animal model, (R) Restricted Estimated Maximum Likelihood, (B) Gibbs sampling (Bayesian Inference), (L) Linear data distribution, (T) Threshold data distribution.

The animals in this study who survived until weaning had an average of 176.15 (59.19) $\mathrm{kg}$ body live weight and age at weaning of 195.26 (54.05) days. Higher weights at weaning were reported by Ribeiro et al. (2015) that found Nellore animals with an average weight weaning of $188.10 \mathrm{~kg}$, and by Pedrosa et al. (2014), who found an average weight of $190.09 \mathrm{~kg}$ for calves of the same breed.

Genetic analysis of weaning weight, regardless of the model seen in Table 5, resulted in estimated components (co) variance and genetic parameters higher than those reported in the literature. Evaluating Pooled Nellore in the northeast of Brazil, Amaral et al. (2014) estimated heritability of 0.19 for weight adjusted to 205 days in single trait analysis. Araújo et al. (2014) reported estimates of 0.36 for weight at 210 days in Nellore cattle.

As reported by Ribeiro et al. (2001) and Araujo et al. (2014), moderate to high heritability estimates for weaning weight and low maternal heritability for weaning weight indicate less reliance on descendants to get higher weights due to the contribution of their mothers, which shows that the most significant part of total variability is due to genetic additive action. This explains partially the low covariance, and further, the negative covariance between direct and maternal genetic effects $\left(\sigma_{\mathrm{a}, \mathrm{m}}\right)$ recorded with different adjusted models (Tables 4 and 5). The different estimates reported in the literature also reflect the genetic diversity found in different regions of Brazil, since differences in allele frequencies result in changes in additive genetic variance and consequently on the estimates of heritability (Boligon et al., 2010).

The negative genetic correlation between the observed SW and WW traits (Table 5) indicates antagonism between them. However, this antagonism is favorable because it indicates that the same genes that act favorably to the increase in weaning weight of calves also contribute to a reduction in the phenotype for the SW trait, which in this study was classified as 1 (live calves until weaning ) and 2 (dead calves). Therefore, calves with superior genotypes for higher weights at weaning tend to have more chances of survive until stage of weaning.

The comparison between different estimation method in single or two-trait analysis models allow the conclusion that the most appropriate model for the analysis of calf survival until weaning was the model consists of the Bayesian estimation method, in animal model and assuming linear distribution for phenotypes subject to the single trait analysis. Negative genetic correlation between SW and WW traits was observed indicating that the same genes that act favorably to the increase in weaning weight of calves also contribute to a reduction for preweaning mortality.

\section{Acknowledgements}

To the Agropecuaria CFM Ltda for providing the data and information used in this study, the University of São Paulo by the structure necessary for the development of this project. To the Coordenação de Aperfeiçoamento de Pessoal de Nível Superior-CAPES (process 3048/2010), Fundação de Amparo à Pesquisa do Estado de São Paulo-FAPESP (process 2012/50533-2 and 2104/07566-2) and Conselho Nacional de Desenvolvimento Científico e Tecnológico-CNPq for financial support. 


\section{References}

Amaral, R. D. S., Carneiro, P. L. S., Ambrosini, D. P., \& Malhado, C. H. M. (2014). Trends, phenotypic and genetic parameters for growth traits in cattle Nellore polled Northeast Brazilian. Revista Brasileira de Saúde e Produção Animal, 15(2), 261-271. https://doi.org/10.1590/S1519-99402014000200003

Araújo, C. V. D., Lôbo, R. B., Figueiredo, L. G. G., Mousquer, C. J., Laureano, M. M. M., Bittencourt, T. C. B. D. S., \& Araújo, S. I. (2014). Estimates of genetic parameters of growth traits of Nellore cattle in the Midwest region of Brazil. Revista Brasileira de Saúde e Produção Animal, 15(4), 846-853. https://doi.org/10.1590/S1519-99402014000400006

Azzam, S. M., Kinder, J. E., Nielsen, M. K., Werth, L. A., Gregory, K. E., Cundiff, L. V., \& Koch, R. M. (1993). Environmental effects on neonatal mortality of beef calves. Journal of Animal Science, 71(2), 282-290.

Boligon, A. A., Albuquerque, L. G., Mercadante, M. E. Z., \& Lôbo, R. B. (2010). Study of relations among age at first calving, average weight gains and weights from weaning to maturity in Nellore cattle. Brazilian Journal of Animal Science, 39(4), 746-751. https://doi.org/10.1590/S1516-35982010000400007

Bourdon, R., \& Golden, B. (2000). EPD and economics determining the relative importance of traits. Retrieved November 18, 2016, from $\mathrm{http} / / /$ beefmagazine.com/mag/beef_epds_economics_determining.

Carneiro Júnior, J. M., Euclydes, R. F., Lopes, P. S., \& Torres, R. A. (2004). Evaluation of the variance component estimation methods using simulate data. Brazilian Journal of Animal Science, 33(2), 328-336. https://doi.org/10.1590/S1516-35982004000200008

Casas, E., Thallman, R. M., \& Cundiff, L. V. (2011). Birth and weaning traits in crossbred cattle from Hereford, Angus, Brahman, Boran, Tuli, and Belgian Blue sires. Journal of Animal Science, 89(4), 979-987. https://doi.org/10.2527/jas.2010-3142

Cole, J. B., Wiggans, G. R., VanRaden, P. M., \& Miller, R. H. (2007). Stillbirth (co)variance components for a sire-maternal grandsire threshold model and development of a calving ability index for sire selection. Journal of Dairy Science, 90(5), 2489-2496. https://doi.org/10.3168/jds.2006-436

Corrêa, E. S., Andrade, P., Euclides Filho, K., \& Alves, R. G. O. (2000). Evaluation of a beef cattle production system. 1. Reproductive performance. Brazilian Journal of Animal Science, 29(6), 2209-2215.

Euclides Filho, K. (2000). Produção de bovinos de corte e o trinômio genótipo-ambiente-mercado. Produção de bovinos de corte (pp. 93-115). Campo Grande, Brasil: Embrapa Gado de Corte.

Everling, D. M., Bresolin, T., Rorato, P. R., Araujo, R. O., Boligon, A. A., Weber, T., ... Campos, L. T. (2014). Finishing precocity visual score and genetic associations with growth traits in Angus beef cattle. Genetics and Molecular Research, 13(3), 7757-776. https://doi.org/10.4238/2014.September.26.13

Faria, C. U., Iwres, B. C., Vozzi, A. P., Magnabosco, C. U., Koury Filho, W., Viu, M. A., Oliveira, H. N., \& Lôbo, R. B. (2010). Genetic correlations between categorical morphological traits in Nellore cattle by applying Bayesian analysis under a threshold animal model. Journal of Animal Breeding and Genetics, 127(5), 377-384. https://doi.org/10.1111/j.1439-0388.2010.00860.x

Faria, C. U., Magnabosco, C. U., Albuquerque, L. G., Los Reyes, A., Bezerra, L. A. F., \& Lôbo, R. B. (2008). Genetic analysis for visual scores of bovines with the linear and threshold Bayesian models. Pesquisa Agropecuária Brasileira, 43(7), 835-841. https://doi.org/10.1590/S0100-204X2008000700007

Forutan, M., Mahyari, S. A., \& Sargolzaei, M. (2015). Genetic evaluation of calf and heifer survival in Iranian Holstein cattle using linear and threshold models. Journal of Animal Breeding and Genetics, 132(1), 51-58. https://doi.org/10.1111/jbg.12115

Gianola, D., \& Foulley, J. L. (1983). Sire evaluation for ordered categorical data with a threshold model. Genetics Selection Evolution, 15(2), 201-224. https://doi.org/10.1186/1297-9686-15-2-201

Gilmour, A. R., Gogel, B. J., Cullis, B. R., Welham, S. J., \& Thompson, R. (2015). ASReml User Guide Release 4.1 Functional Specification. VSN International Ltd., Hempstead, UK.

Goyache, F., Gutiérrez, J. P., Alvarez, I., Fernández, I., Royo, L. J., \& Gómez, E. (2003). Genetic analysis of calf survival at different preweaning ages in beef cattle. Livestock Production Science, 83(1), 13-20. https://doi.org/10.1016/S0301-6226(03)00044-7

Guerra, J. L. L., Franke, D. E., \& Blouin, D. C. (2006). Genetic parameters for calving rate and calf survival from linear, threshold, and logistic models in a multibreed beef cattle population. Journal of Animal Science, 
84(12), 3197-3203. https://doi.org/10.2527/jas.2006-007

Hansen, M., Madsen, P., Jensen, J., Pedersen, J., \& Christensen, L. G. (2003). Genetic parameters of postnatal mortality in Danish Holstein calves. Journal of Dairy Science, 86(5), 1807-1817. https://doi.org/10.3168/jds.S0022-0302(03)73766-7

Henderson, C. R. (1953). Estimation of variance and covariance components. Biometrics, 9(2), $226-252$. https://doi.org/10.2307/3001853

Misztal, I., Tsuruta, S., Lourenço, D., Aguilar, I., Legarra, A., \& Vitezica, Z. (2015). Manual for BLUPF90 family of programs. University of Georgia, Athens, GA, USA.

Nelder, J. A., \& Wedderburn, R. W. M. (1972). Generalized Linear Models. Journal of the Royal Statistical Society: Series A (Statistics in Society), 135(3), 370-384. https://doi.org/10.2307/2344614

Nix, J. M., Spitzer, J. C., Grimes, L. W., Burns, G. L., \& Plyler, B. B. (1998). A retrospective analysis of factors contributing to calf mortality and dystocia in beef cattle. Theriogenology, 49(8), 1515-1523. https://doi.org/10.1016/S0093-691X(98)00097-1

Patterson, H. D., \& Thompson, R. (1971). Recovery of inter-block information when block sizes are unequal. Biometrika, 58(3), 545-554. https://doi.org/10.1093/biomet/58.3.545

Pedrosa, V. B., Eler, J. P., Ferraz, J. B. S., \& Pinto, L. F. B. (2014). Utilization of single-trait and multi-trait models applied to genetic parameter estimation in Nellore Cattle. Arquivo Brasileiro de Medicina Veterinária e Zootecnia, 66(6), 1802-1812. https://doi.org/10.1590/1678-6170

Queiroz, S. A., Oliveira, J. A., Costa, G. Z., \& Fries, L. A. (2011). Estimates of genetic parameters for visual scores and daily weight gain in Brangus animals. Animal, 5(6), 838-843. https://doi.org/10.1017/ S1751731110002442

Ray, D. E., Itulya, S. B., Roubicek, C. B., \& Benson, C. R. (1989). Pregnancy rate, calf mortality and calving date in unsupplemented Hereford range cows. Livestock Production Science, 23(3-4), 305-315. https://doi.org/10.1016/0301-6226(89)90079-1

Ribeiro, M. N., Pimenta Filho, E. C., Martin, G. A., Sarmento, J. L. R., \& Martins Filho, R. (2001). Heritability of maternal and direct effects of growth traits in Nellore herds at Paraiba state. Brazilian Journal of Animal Science, 30(4), 1224-1227. https://doi.org/10.1590/S1516-35982001000500014

Ribeiro, S., Eler, J. P., Pedrosa, V. B., Rosa, G. J. M., Ferraz, J. B. S., \& Balieiro, J. C. C. (2015). Genotype x environment interaction for weaning weight in Nellore cattle using reaction norm analysis. Livestock Science, 176, 40-46. https://doi.org/10.1016/j.livsci.2015.03.032

Riley, D. G., Chase Jr, C. C., Olson, T. A., Coleman, S. W., \& Hammond, A. C. (2004). Genetic and nongenetic influences on vigor at birth and preweaning mortality of purebred and high percentage Brahman calves. Journal of Animal Science, 82(6), 1581-1588. https://doi.org/10.2527/2004.8261581x

Riley, D. G., Sanders, J. O., Knutson, R. E., \& Lunt, D. K. (2001a). Comparison of F1 Bos indicus x Hereford cows in central Texas: I. Reproductive, maternal, and size traits. Journal of Animal Science, 79(6), 1431-1438. https://doi.org/10.2527/2001.7961431x

Riley, D. G., Sanders, J. O., Knutson, R. E., \& Lunt, D. K. (2001b). Comparison of F1 Bos indicus x Hereford cows in central Texas: II. Udder, mouth, longevity, and lifetime productivity. Journal of Animal Science, 79(6), 1439-1449. https://doi.org/10.2527/2001.7961439x

Santana Jr, M. L., Eler, J. P., Cucco, D. C., Bignardi, A. B., \& Ferraz, J. B. S. (2013). Genetic associations between hip height, body conformation scores, and pregnancy probability at 14 months in Nellore cattle. Livestock Science, 154(1-3), 13-18. https://doi.org/10.1016/j.livsci.2013.02.018

Schmidek, A., Costa, M. J. R. P., Mercadante, M. E. Z., Toledo, L. M., Cyrillo, J. N. S. G., \&, Branco, R. H. (2013). Genetic and non-genetic effects on calf vigor at birth and preweaning mortality in Nellore calves. Brazilian Journal of Animal Science, 42(6), 421-427. https://doi.org/10.1590/S1516-35982013000600006

Searle, S. R. (1987). Linear Models for Unbalanced data. John Wiley, New York, NY, USA.

Silva, L. C. M., Baldi, F., Aboujaoude, C., Venturini, G. C., Albuquerque, L. G., \& Costa, M. J. R. P. (2017). Genetic parameter estimates for prenatal and postnatal mortality in Nellore cattle. Journal of Animal Breeding and Genetics, 134(1), 27-33. https://doi.org/10.1111/jbg.12246 
Van Tassell, C. P., Van Vleck, L. D., \& Gregory, K. E. (1998). Bayesian analysis of twinning and ovulation rates using a multiple: Trait threshold model and Gibbs sampling. Journal of Animal Science, 76, 2048-2061. https://doi.org/10.2527/1998.7682048x

\section{Copyrights}

Copyright for this article is retained by the author(s), with first publication rights granted to the journal.

This is an open-access article distributed under the terms and conditions of the Creative Commons Attribution license (http://creativecommons.org/licenses/by/4.0/). 